\title{
Commentary
}

\section{Child maltreatment surveillance: enumeration, monitoring, evaluation and insight}

\author{
Rebecca T. Leeb, PhD (1)*; John D. Fluke, PhD (2)
}

Public health surveillance is "the ongoing systematic collection, analysis and interpretation of outcome-specific data for use in the planning, implementation, and evaluation of public health practice, closely integrated with the timely dissemination of these data to those who need to know."1(p. 164) Sustainable surveillance systems are thus generally designed with three functional goals in mind: enumeration, monitoring and evaluation. This framework evolved from efforts to prevent and control infectious disease, and more recently has been applied to other health problems, such as violence, that impact communities and society. ${ }^{2,3}$

Application of epidemiologic surveillance to child abuse and neglect (CAN) presents specific challenges related to varying definitions and incident reporting. Definitions of abuse and neglect differ within and across countries, obscuring estimates of the true magnitude of the problem. Definitions also vary depending on the nature of the child protection system. ${ }^{4}$ Countries may lack legal or social systems with specific responsibility for responding to and recording reports of CAN, particularly countries where populations are remote or in flux (e.g. due to conflict). Underreporting of CAN results in underestimates of prevalence. Violence by caregivers toward children is often known only to the perpetrator, and depending on the developmental capacity of the child, the victim. Further, CAN cases may be reported to a wide variety of sentinels (e.g. educators, clergy, physicians, law enforcement, child welfare), or may not be reported to any official source at all. Social stigma and unintended consequences of reporting, as well as cultural and political barriers, also impact reporting both within communities and globally.

These challenges notwithstanding, epidemiological CAN surveillance systems exist in many, but not all, high-income countries and a growing number of middle and lowincome countries. Surveillance in highincome countries commonly relies on data collected from child welfare agencies or from professionals who come into contact with children. The Canadian Incidence Study of Reported Child Abuse and Neglect (CIS), described in this special issue, includes data on CAN reported to child welfare agencies. Data are collected periodically by survey and analyzed to estimate incidence rates. Other data collection programs with similar sample-based survey methods such as the U.S. National Incidence Study of Child Abuse and Neglect (NIS) obtain data from child welfare agencies, but also from professionals in other settings who come into contact with children. ${ }^{5}$

Like the CIS, the U.S. National Child Abuse and Neglect Data System (NCANDS) is based on child welfare data, but uses a different methodology. States and territories submit administrative data on all children who are reported to the social welfare system for suspected abuse and neglect to NCANDS for analysis of prevalence and trends annually. Similar systems relying on administrative data from child welfare are in use elsewhere including the United Kingdom $^{6}$ and Australia ${ }^{7}$ to name a few. Saudi Arabia has developed a surveillance system using hospital-based child protection teams rather than child welfare data. ${ }^{4}$

CAN surveillance in low- and middleincome countries, especially those with limited social services infrastructure, commonly rely on surveys asking children, and caregivers about current and past experiences of CAN. Examples of survey surveillance include the Violence Against Children Surveys (VACS) implemented in countries such as Cambodia, Haiti, Kenya, Malawi, Swaziland, Tanzania and Zimbabwe, ${ }^{8}$ and the UNICEF Multiple Indicator Cluster Surveys (MICS) which has been implemented in more than 100 low- and middleincome countries. ${ }^{9}$ Self-report surveys, such as the U.S.-based National Survey of Children's Exposure to Violence (Nat SCEV), ${ }^{10}$ are also used in high-income countries because they are able to provide a broader range of information and perspective on maltreatment incidence and prevalence than administrative data or samples based on surveys of child serving professionals. However, these surveys are also subject to unique biases.

The lack of consistent case definitions and a systematic approach to data collection across available CAN surveillance systems suggests that the three functional surveillance goals may be necessary but not sufficient to achieve a full understanding

Author references:

1. Division of Human Development and Disability, National Center on Birth Defects and Developmental Disabilities, Centers for Disease Control and Prevention, Atlanta, GA, US 2. Department of Pediatrics, Kempe Center for the Prevention \& Treatment of Child Abuse \& Neglect, University of Colorado School of Medicine, Aurora, CO, US

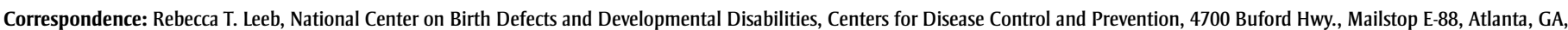
30341-3717; Tel: 404-498-6752; Fax: 404-498-0270; Email: RLeeb@CDC.gov

*The findings and conclusions in this report are those of the author(s) and do not necessarily represent the official position of the Centers for Disease Control and Prevention. 
of the magnitude and nature of CAN. Efforts to develop more uniform definitional approaches for administrative sources have been made, but despite these attempts, it remains challenging to proffer accepted definitions in complex policy environments with multiple inter-sectorial stakeholders. ${ }^{11}$ Further, we and others (e.g. Thacker) suggest that surveillance systems in CAN are incomplete if they do not strive to achieve some degree of insight about the data collection methods, the process of surveillance, or the underlying risk conditions. ${ }^{12}$

\section{Insight}

Insight can be considered as a generative analytic activity that amplifies information in a way that has implications for future surveillance and prevention efforts. It can also be characterized as a one-time event or gain; once insight is attained awareness of it can only be documented or replicated, and surveillance activities return to more attenuated enumeration, monitoring and evaluation efforts. Below we highlight four ways in which CAN surveillance has produced insights thus far.

1. How you count matters. Relying on a single source of information such as cases reported to child welfare agencies or self-report surveys provides only one view of the problem. Available data suggest that systematic triangulation of data sources is needed to fully address functional surveillance objectives and generate a complete picture of the magnitude of CAN. ${ }^{13,14}$ Linking administrative data to common identifiers from a range of service systems is one method of triangulation, but requires adjustments to address non-uniformity of data from different sources. The Developmental Pathways Project in Western Australia has achieved success using this method of triangulation with notable impacts on knowledge and policy. ${ }^{15,16}$ The NIS in the United States uses a different approach to triangulation in which periodic survey data are collected from a wide variety of sentinels. ${ }^{17}$ This approach has provided direction and focus for U.S. policy and practice efforts, ${ }^{18,19}$ but lengthy periodicity and cost of data collection makes determination of the direct impact of survey data on changes in policy and practice difficult to assess.

2. Who and what is being counted matters. For example, NCANDS provides both unique and duplicate counts in their annual report. The unique count is the number of children who experience maltreatment in a given year. The duplicate count is the number of reports received by child welfare in the given year. Thus, one provides a count of children who are maltreated while the other provides the number of incidents of abuse and/or neglect.

3. Sustainability of national surveillance systems is critical and challenging. Without regular, ongoing surveillance insight is limited to a snapshot in time; at best, one-off studies address only short-term policy goals. Systems that collect data on a periodic basis, regardless of methodology, expand the snapshot but may lack the specificity to examine the impact of incremental changes over time. The efforts by UNICEF using the MICS to track indicators of harm and exploitation of children demonstrates that sustained CAN surveillance is feasible for countries, regardless of resource limitations. ${ }^{20}$

4. The focus and scope of the surveillance system impacts the resulting data. Systems may focus on morbidity, mortality, or both, and could thus lead to different conclusions about CAN. Inclusion of indicators, risk and protective factors will impact what can be learned from the data. For example, analysis of data from surveillance of children in the welfare system revealed insight into relative risk of repeat maltreatment for children with a disability and underlined the importance of collecting data about disabilities and other potential risk factors for enumeration, monitoring and evaluation. ${ }^{21}$
These insights are consistent with concepts discussed in the U.S. Centers for Disease Control and Prevention's Updated Guidelines for Evaluating Public Health Surveillance Systems. ${ }^{22}$ Not only can insight derived from CAN surveillance aid in evaluating and improving surveillance systems, it can also be the catalyst for those who set policy and implement programs. Relevant information, when appropriately translated, can be used in efforts to reduce violence against children and to promote relationships and environments in which children thrive. As noted by Thacker, "Unless [surveillance] information is provided to those who set policy and implement programs, its use is limited to archives and academic pursuits....,12 (p. 5) Thus, surveillance data must be available and accessible to key stakeholders.

CAN surveillance remains a challenge for epidemiologists worldwide. But insights derived from our collective efforts, including the CIS, will help target our prevention efforts in the face of this global public health problem.

\section{References}

1. Thacker SB, Berkleman RL. Public health surveillance in the United States. Epidemiol Rev. 1988;10:164-90.

2. Dahlberg LL, Mercy JA. History of violence as a public health problem. AMA J Ethics. 2009;11(2):167-172.

3. Lee LM, Teutsch SM, Thacker SB, St. Louis ME. (eds). Principles and practice of public health surveillance. Oxford Scholarship Online; 2010. DOI: 10.1093/acprof:oso/ 9780193572922.001 .0001

4. AlEissa MA, Fluke JD, Gerbaka B, et al. A commentary on national child maltreatment surveillance systems: examples of progress. Child Abuse Neg. 2009;33(11):809-814.

5. Sedlak AJ, Mettenberg J, Basena M, et al. Fourth National Incidence Study of Child Abuse NIS-4: report to Congress. Washington, DC: Department of Health and Human Services, Administration for Children and Families; 2010 
6. Department for Education (UK). Statistical release: referrals, assessments and children who were the subject of a child protection plan (Children in need census - provisional) year ending 31 Mar 2011 [Internet]. London (England): Department for Education; 2011 [cited 2015 June 17]. Available from: https://www.gov.uk/government/statistics/ referrals-assessments-and-children-who-werethe-subject-of-a-child-protection-plan-childrenin-need-census-2010-to-2011-provisional

7. Australian Institute of Health and Welfare. Child protection Australia: 2011-12. Child welfare series no. 55. Canberra: AIHW; 2013. [Catalogue No.: CWS 43].

8. Centers for Disease Control and Prevention. Towards a violence-free generation: Using science to fuel action and end violence against children [Internet]. Cited 2015 June 17. Available from: http://www.cdc.gov/ violenceprevention/vacs/index.html

9. UNICEF. Multiple Indicator Cluster Surveys [Internet]. UNICEF; 2015 [cited 2015 June 17]. Available from: http://mics.unicef. org/surveys

10. Finkelhor D, Shattuck A, Turner HA, Hamby SL. Trends in children's exposure to violence, 2003 to 2011. JAMA Pediatr. 2014;168(6): 540-546.

11. Leeb RT, Paulozzi LJ, Melanson C, Simon TR, Arias I. Child maltreatment surveillance: uniform definitions for public health and recommended data elements, version 1.0. Atlanta (GA): Centers for Disease Control and Prevention, National Center for Injury Prevention and Control; 2006.

12. Thacker S. Historical Development. Lee LM, Teutsch SM, Thacker SB, St Louis ME, eds. Principles and practice of public health surveillance, 3rd ed. New York: Oxford University Press; 2010. pp. 1-17.

13. Gibbs D, Rojas-Smith L, Wetterhall S, et al. Improving identification of child maltreatment fatalities through public health surveillance. J Public Child Welf. 2013;7:1-19.

14. Krug EG, Dahlberg LL, Mercy JA, Zwi AB, Lozano $\mathrm{R}$, eds. World report on violence and health. Geneva (Switzerland): World Health Organization; 2002.
15. Government of Western Australia, Department of Health. Data linkage Western Australia: Enabling health \& medical research in Western Australia [Internet]. Data Linkage WA; 2015 [cited 2015 June 17]. Available from: http:// www.datalinkage-wa.org/

16. Brook EL, Rosman DL, Holman CDJ, Trutwein B. Summary report: research outputs project, WA data linkage unit (1995-2003) [Internet]. Department of Health, Government of Western Australia; 2005 [cited 2015 June 17]. Available from http://www.datalinkage-wa. org.au/sites/default/files/Summary \% 20of \% 20Research \%200utputs \%20Project.pdf

17. U.S. Department of Health and Human Services. The Fourth National Incidence Study of Child Abuse and Neglect [Internet]. Cited 2015 June 17. Available from: https://www.nis4.org/index.htm

18. Daro D. Child abuse prevention: a job half done. Chicago: Chapin Hall at the University of Chicago; 2010.

19. Russell J, Cooper C. Technical assistance brief, the NIS-4: what it all means (and doesn't mean) [Internet]. Reno (NV): National Council of Juvenile and Family Court Judges; 2011 [cited 2015 June 17]. Available from: http://www.ncjfcj.org/ sites/default/files/nis-4\%20technical $\% 20$ assistance $\% 20$ brief.pdf

20. Sumner SA, Mercy JA, Saul J, et al. Prevalence of sexual violence against children and use of social services - seven countries, 2007-2013. MMWR. 2015;64(21):565-569.

21. Fluke J, Shusterman G, Hollinshead D, Yuan YT. Longitudinal analysis of repeated child abuse reporting and victimization: multistate analysis of associated factors. Child Maltreatment. 2008;13(1):76-88.

22. Centers for Disease Control and Prevention. Updated Guidelines for Evaluating Public Health Surveillance Systems [Internet]. MMWR. 2001;50(RR13):1-35. [cited 2015 September 8]. Available from: http://www. cdc.gov/mmwr/preview/mmwrhtml/rr5013 a1.htm 